\title{
EXTRACTOS DE REVISTAS
}

\section{COLAPSO VASOMOTOR EN EL POST-PARTO INMEDIATO DE LA TOXEMICA}

Tatum and Mulé Am. J. Obst \& Gyn. Marzo 1956. Pág. 492.

El desarrollo del colapso vasomotor en la paciente toxémica, durante las primeras 24 horas de puerperio, ha sido estudiado con particular interés sobre el metabolismo electrolítico.

Las concentraciones séricas de sodio, potasio y cloruros, fueron determinadas coincidencialmente con la presencia de colapso vascular en 8 pacientes. Las concentraciones de sodio y cloruros fueron muy bajas en todos los casos. La concentración de potasio se encontró por encima de los valores de control. La similitud tanto clínica como química, con el colapso vasomotor observado en la insuficiencia aguda cortico-suprarrenal sugiere el uso cel cloruro de sodio, como un agente terapéutico en estos casos.

Diez y seis pacientes han sido tratados con soluciones tanto hipertónicas como isotónicas de cloruro de sodio, por vía endovenosa, habiéndose recobrado rápidamente y en ocasiones en forma dramática, del estado de colapso vasomotor.

No se registró ninguna defunción en las pacientes estudiadas.

\section{EL SINDROME DE STEIN LEVENTHAL}

\section{Por Irvin F. Stein}

Tomado de "Obstetricia y Ginecología". Tomo 15. № 2. 1955. Págs. 699 a 713.

El autor manifiesta haber empleado en los últimos 26 años la resección cuneiforme de los ovarios y la recomienda como tratamiento de rutina en aquel sindrome caracterizado por amenorrea y/o hirsutismo acompañado de ovarios poliquísticos.

La ovarítis poliquística bilateral se presenta tan solo en un pequeño número de pacientes de infertilidad y además de los síntomas clásicos antes anotados se pueden presentar otros, tales 
como las menometrorragias que casi siempre terminan en ame. norrea.

En muchas oportunidades la presencia de ovarios poliquísticos puede ser demostrabie al simple examen bimanual, pero en otras, por razones de rigidez de la pared abdominal $u$ obesidad puede llegar a ser imposible.

Teniendo en cuenta que la ginecografía simple con neumoperitone'o arrojaba datos de valor en otras afecciones pélvicas, el autor la empleó posteriormente en las estériles, descubriendo en esta forma muchos casos de ovarios poliquísticos bilaterales apreciando "ovarios simétricamente grandes con útero relativamente pequeño".

El diagnóstico positivo del sindrome solo puede hacerse mediante la adecuada identificación del agrandamiento simétrico de los ovarios, y cuando el examen ginecológico simple no arroja resuitados satisfactorios, se puede acudir a los siguientes métodos auxiliares: a) Examen bajo anestesia; b) Culdoscopia; c) Colpotomía, y d) Ginecografía.

Se citan algunos otros métodos que no parecen tener algún valor verdaderamente positivo. Por ejemplo los frótis vaginales se parecen a los que se encuentran en la segunda semana del ciclo. En cuanto al moco cervical, se aprecia una disminución y un Spinnbarkeit de 1 a 2 ctms. El metabolismo basal no experimenta variaciones. Las biopsias de endometrio son de valor discutible especialmente en las que se encuentran en amenorrea. Las c.eterminaciones de 17 cetoesteroides se encuentran dentro de los límites normales o ligeramente elevadas y por ello se cree que el hirsutismo y otras características resulten de verdadera desfeminización y nó por efectos androgénicos. Las curvas de T. B. son de valor en el diagnóstico positivo y son por lo común monofási. cas indicando por io tanto ciclos anovulatorios.

Después de utilizar todos los auxiliares diagnósticos enumerados, concluye el autor que la ginecografía con neumoperitoneo se dabe realizar siempre que se sospeche la presencia de ovarios poliquísticos, y sostiene que en todos los casos en que se obtuvo ta imagen de ovarios agrandados se pudo corroborar el hecho a ia laparotomía.

El autor posee poca experiencia en el tratamiento del síndrome mediante el empleo de los rayos $\mathrm{x}$, y en cambio preconiza el tratamiento quirúrgico (resección cuneiforme), con el cual en 
578 pacientes obtuvo un $75 \%$ de menstruaciones regulares, $37 \%$ de embarazos con 215 nacimientos vivos.

Recomienda la simple resección cuneiforme de los ovarios sin adicionar otros procedimientos quirúrgicos. No es partidario de la punción a través de la cápsula por creer que tal trauma acarrea la formación de adherencias. La apendicectomía profiíáctica la proscribe puesto que el ovario incidido es extremadamente vulnerable a la infección.

Finalmente comenta el doctor stein, en cuanto a ios resultados quirúrgicos se refiere, que la producción de adherencias uváricas puede hacer fracasar por completo el propósito de la intervención.

R. R.

\title{
TRATAMIENTO DE LA ENDOMETRIOSIS CON STILBESTROL MICROMIZADO Y VITAMINIZADO
}

\author{
Karl John Karnaky M. D.
}

Profesor Asistente de Clínica Ginecológica de Baylor University.

El Stilbestrol micronizado y vitaminizado se prepara en tabletas en dosificación de 1 y 25 mlgrs. teniendo la ventaja de no producir náuseas y vómitos, o de hacerlo en muy escasa pro. porción.

La administración fue la siguiente: Se comienza con 1 tableta de 1 migr., tomada a las 21 horas, se aumenta 1 tableta todas las noches, durante 6 noches; luego se sigue con 1 tableta de 25 milgr. y se aumenta también una diaria hasta llegar a dar cuatro; se trataron un total de 75 pacientes.

De aparecer náuseas y vómitos, se administrarán dos tabletas cada 15 minutos, repetir dos a cuatro veces o hasta que las reacciones inconvenientes hayan sido dominadas. La dosificación máxima de 100 mlgrs. se mantendrá de tres a nueve meses y aún más según la gravedad de los síntomas.

Si durante el tratamiento aparecen metrorragias, la paciente tomará dos a cuatro tabletas de Estrógeno de 25 mlgrs. cada 15 minutos hasta que los síntomas sean dominados, aigunas requieren hasta 150 y 400 mlgrs. diarios para permanecer amenorréicas. Cuando el estrógeno ha sido administrado durante el lapso deseado la reducción se hace gradualmente. 
La hipótesis sobre la posibilidad de causa de las náuseas por el Stilbestrol, se deberá a que el "preestrógeno libre e inactivo" (Stilbestrol), libre en la sangre, estimularía el centro emetogénico; las vitaminas dadas en dosificación equilibrada facilitarían la transformación del preestrógeno en substancia estrogénica carente de acción irritativa sobre el centro del vómito.

La mayor parte de las enfermas se adaptan a esta forma de administración dentro de los cuatro a siete dias de iniciada. Si las náuseas y vómitos continúan se recurrirá a supositorios de Nembutal.

La edad promedio de las enfermas tratadas fue de treinta años. Casadas $90 \%$; aquejaban esterilidad $52 \%$. Habian tenido embarazo 44. Ciclos regulares en 58 casos. Acusaban dolores abdominales el $90 \%$. Pacientes que tuvieron intervenciones quirúrgicas anteriores, 28 casos.

Los resultados fueron los siguientes: dolor intermenstrual aliviado 28 casos, $78 \%$.

Dismenorrea completamente aliviada, 46 casos $(64 \%)$.

Dismenorrea no mejorada, 2 casos.

Mejoría de la dispareunia, 19 casos.

Embarazadas después del tratamiento, 24 casos, 17 de ellas eran estériles. Partos a término, 20.

Ultimo examen: 9 casos mostraban rastros de endometriosis en los órganos pelvianos. (11,5\%) y 68 mostraban órganos libremente móviles $(88.75 \%)$.

Recurrencia, 3 casos.

A 42 pacientes laparotomizadas por diversas razones se im. plantó en la incisión tejido endometrial. En ninguna de estas se desarrolló el endometrio implantado cuando se les sometió al tratamiento con Stilbestrol Micronizado, solo o asociado a Progesterona.

Se describe un método de administración de Stilbestrol que se caracteriza por su eficacia y muy buena tolerancia; sería de desear que se adoptara esta terapia durante un lapso por lo menos de 6 meses antes de operar a las enfermas. 